in Dublin who are infected with hepatitis D virus ${ }^{2}$ and the increase of such infections in proportion with infections with human immunodeficiency virus (A G Shattock et al, international symposium on AIDS, Paris 1986) make it likely that other reactivations of infection with hepatitis $D$ virus will occur in this susceptible population.

1 Smith AM, Tedder RS. Development of an enzyme-linked immunosorbent assay (ELISA) for hepatitis B e antigen and antibody: $\mathcal{J}$ Virol Methods 1981;3:1-11.

2 Shattock AG, Irwin F, Morgan BM, et al. Increased severity and morbidity of acute hepatitis in drug abusers with simultaneously acquired hepatitis $\mathrm{B}$ and hepatitis $\mathrm{D}$ virus infections. $\mathrm{Br} \mathrm{Med} \mathcal{f}$ 1985;290:1377-80.

(Accepted 6 March 1987)

Department of Medical Microbiology, University College, Dublin 4

A G SHATTOCK, MA, PHD, college lecturer

H FINLAY, BA (MOD), research assistant

I B HILLARY, MD, FRCPATH, professor of medical microbiology

Correspondence to: Dr Shattock.

\section{Loin pain and haematuria syndrome: possible association with intrarenal arterial spasms}

Loin pain and haematuria syndrome is characterised by repeated attacks of unilateral or bilateral loin pain with haematuria in patients with normal intravenous pyelograms and cystoscopy findings and sterile urine..$^{2} \mathrm{We}$ report the angiographic findings of four such patients studied in 1979-81 and followed up subsequently.

\section{Patients, methods, and results}

During 1979-81 we diagnosed loin pain and haematuria syndrome in four women (mean age 43.5 years (range 38-49)). They all had attacks of severe, incapacitating loin pain associated with microscopic haematuria. The mean duration of their symptoms at the time of diagnosis was 5.8 years (range 2-10). Bleeding times and coagulation function were normal in all patients. Urine was sterile, and no proteinuria was found. Urine cytology, intravenous urography, isotope nephrography, cystoscopy, and ultrasound examination of the kidneys showed no abnormalities. Gynaecological causes of haematuria were excluded. Phase contrast microscopy to determine the origin of the red cells in urine was not performed.

No clinical, microbiological, or serological evidence of systemic autoimmune disease or triggering or precipitating infection was found. All patients were normotensive with normal renal function. Serum concentrations of calcium, phosphate, chloride, sodium, potassium, uric acid, and parathyroid hormone were normal, as were urinary excretions of calcium and phosphate.

A needle biopsy sample taken from the side with loin pain showed only slight arteriolar hyalinosis or mild mesangial cell proliferation. Immunofluorescence studies showed minor deposits of $\mathrm{C} 3$ in the mesangium and in the walls of renal arterioles.

Selective renal angiography with magnification showed no irregularity of the lumen, changes in calibre, or occlusion. In two patients, however, transient vasospasms in intrarenal vessels were noted (figure); in one of these patients the arterial spasms occurred on both sides. During the five year follow up period no underlying diseases or other abnormalities developed.

\section{Comment}

Abnormalities in intrarenal peripheral arteries shown by selective renal angiography have been consistent findings in previous reports. ${ }^{12}$ In our study angiography showed no structural vascular changes in any of the four patients. Transient vasospasms in renal cortical vessels, however, were noted in two patients. According to previous reports renal artery spasms are rarely encountered during routine angiography. ${ }^{3}$ In a series of selective renal angiograms studied using the same magnification technique we found transient arterial spasm in only one of 33 kidneys studied. The present finding of vasospasm in patients with loin pain and haematuria syndrome is therefore unlikely to be merely coincidental.

The renal histological findings in loin pain and haematuria syndrome are similar to those in IgA nephropathy. ${ }^{4}$ Our findings on light microscopy and immunofluorescence studies are in accordance with earlier reports.

Fletcher et al suggested that the loin pain might be caused by renal cortical ischaemia due to vascular occlusions and thrombi. ${ }^{4}$ The disappearance of the pain after autotransplantation suggests, however, that it is mediated through
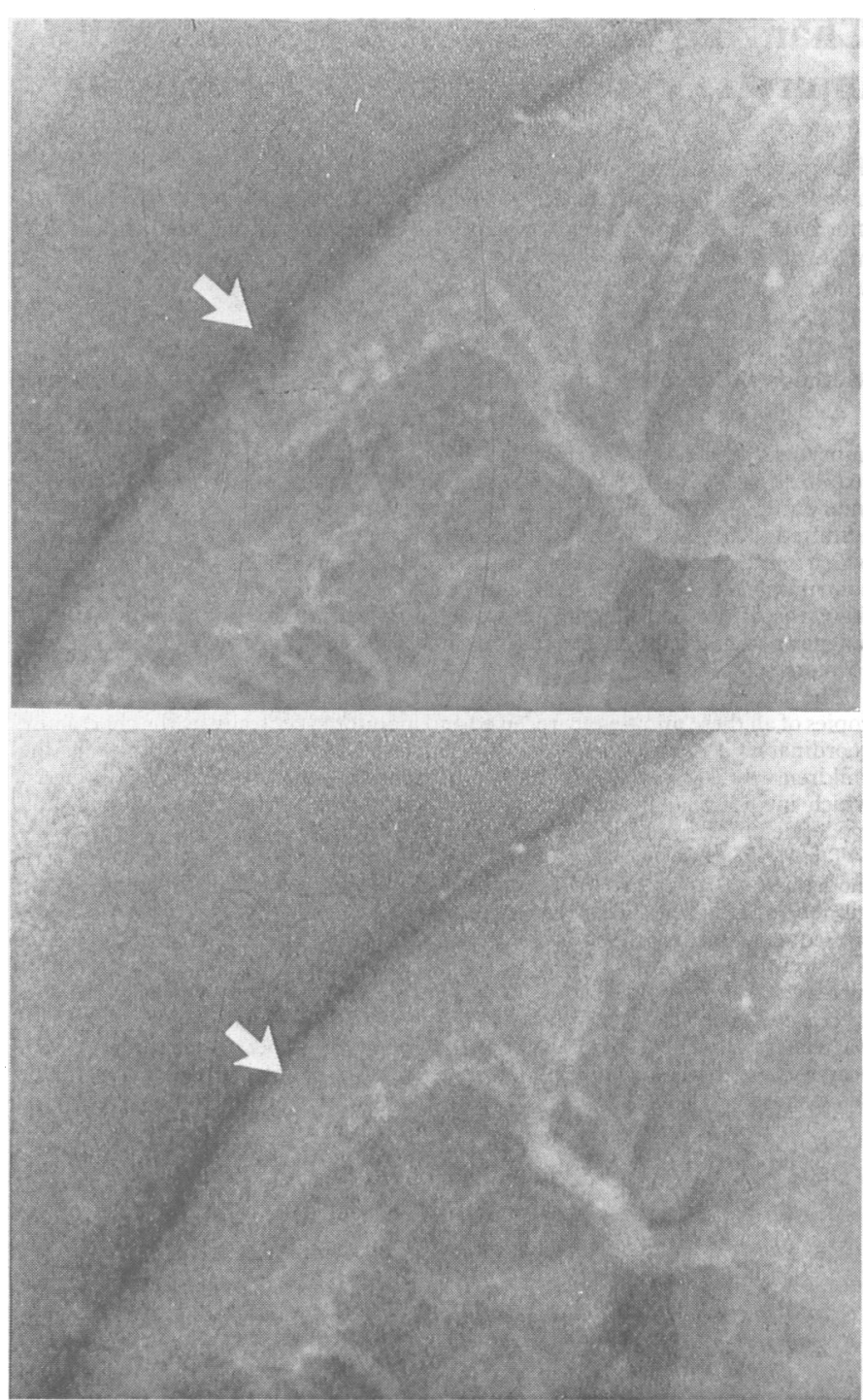

Above: Focused magnification of a selective right renal angiogram which, during the first injection in the arterial phase, shows a cortical perfusion defect (arrow) caused by a vasospasm in a renal cortical vessel. Below: Focused magnification of the same area. No vasospasm is seen during the second injection, given five minutes after the first.

the autonomic nervous system. ${ }^{5}$ Our angiographic findings support this hypothesis. Our findings also show that loin pain and haematuria syndrome may occur in patients who do not have structural changes in the intrarenal peripheral arteries.

This study was supported by grants from the Sigrid Juselius Foundation, the Paulo Foundation, and the Foundation for Research in Rheumatic Diseases.

1 Little PJ, Sloper JS, de Wardener HE. A syndrome of loin pain and haematuria associated with disease of peripheral renal arteries. $Q \mathcal{J}$ Med 1967;36:253-9.

2 Burden RP, Dathan JR, Etherington MD, Guyer PB, MacIver AG. The loin pain/haematuria syndrome. Lancet 1979;i:897-900.

3 Spriggs DW, Brantley RE. Recognition of renal artery spasm during renal angiography. Radiolog 1978;127:363-6.

4 Fletcher P, Al-Khader AA, Parsons V, Aber GM. The pathology of intrarenal vascular lesions associated with the loin-pain-haematuria syndrome. Nephron 1979;24:150-4.

5 Sheil AGR, Ibels LS, Thomas MAB, Graham JC. Renal autotransplantation for severe loin-pain/ haematuria syndrome. Lancet 1985;ii:1216-7.

(Accepted 23 March 1987)

Fourth Department of Medicine, Helsinki University Central Hospital, Unioninkatu 38, SF-00170 Helsinki, Finland

VILLE BERGROTH, MD, junior research fellow

YRJÖ T KONTTINEN, MD, senior research fellow

DAN NORDSTRÖM, MD, house officer

LEENA LAASONEN, MD, consultant in radiology

Correspondence and requests for reprints to: Dr Bergroth. 